\title{
TRANSOMENTAL HERNIATION CAUSING ACUTE INTESTINAL OBSTRUCTION
}

\author{
N. Suresh Kumar¹, Rahul Rai², P. Kulandai Velu³
}

\section{HOW TO CITE THIS ARTICLE:}

N. Suresh Kumar, Rahul Rai, P. Kulandai Velu. "Transomental Herniation Causing Acute Intestinal Obstruction”. Journal of Evolution of Medical and Dental Sciences 2015; Vol. 4, Issue 15, February 19; Page: 2635-2640, DOI: $10.14260 /$ jemds/2015/380

\begin{abstract}
Internal Herniation is an unusual cause of intestinal obstruction ${ }^{1}$ first described by Steinke ${ }^{2}$ in 1932 The incidence of Internal Hernia amongst Acute Intestinal Obstruction in the adult population has been reported as around $0.6-5.8 \%{ }^{3}$ and amongst these, transomental hernias account for about $1-8.9 \%{ }^{4,5}$ They can be congenital or acquired (Trauma, inflammation, age related atrophy. ${ }^{2,6}$ ) There are multiple sites where herniation can occur. There are no specific investigations to rule out internal hernias and should be considered a possibility in cases of acute intestinal obstruction. This patient was operated on early after presentation of acute symptoms and so recovered without any immediate or late post-operative complications.
\end{abstract}

KEYWORDS: Obstruction, transomental, congenital, acquired.

CASE REPORT : A 55 years old male was received in the casualty with the complaints of abdominal pain, distension with nausea and vomiting since 2 days. He had not passed stools since 2 days and flatus since the previous evening. He is a known Hypertensive on irregular treatment. Physical Examination revealed mild abdominal distension, palpable small bowel loops and a collapsed rectum with faecal matter. Bowel sounds were hyperactive with Borborygmi sounds. Patient was afebrile, Pulse rate - 64/ min B.P - 170/100 mm hg. Serum creatinine levels were raised. The first plain abdominal X-ray revealed only intestinal gas with distended bowel loops in upper left quadrant. A Ryles tube was inserted which drained around $500 \mathrm{ml}$ of bilious fluid after which abdominal girth deceased from 73 to $67 \mathrm{~cm}$. Plain CT abdomen revealed pneumomediastinum, an over distended stomach with the tip of the Ryles tube in the Left Iliac fossa, multiple dilated small bowel loops with a segmental collapse in the Ileum.

There was a thin rim of air under the Left dome of the diaphragm but there were no clinical signs of hollow viscous perforation, only subacute intestinal obstruction. The patient was kept under observation and was conservatively managed for 2 days in which period, the vitals were stable, there was maintenance of saturation, there was no abdominal guarding or rigidity and no increase in abdominal girth. After 2 days, repeat X-ray and CT abdomen still showed dilated small bowel loops with multiple air fluid levels and signs of impending small bowel gangrene and was thus shifted for an Emergency Open Explorative Laparotomy. There was an internal herniation of distal end of stomach, gastrocolic omentum, gastroduodenum and Rt. $2 / 3$ rds of the transverse colon which appeared to be abnormally pulled subhepatically, but could not be reduced.

The C-loop of the duodenum with the head of pancreas was in fact an S-loop, with pancreas occupying one convexity. The DJ flexure was in the normal position. The caecum was in the Rt. Iliac fossa ruling out malrotation. About $10 \mathrm{~cm}$ of the jejunum, the entire ileum was occupying the Rt. Side of the abdominal cavity and irreducible. Part of the ileal segment was congested. There were no signs of gangrene. The duodenum was kocherised and reduced through the lesser omentum where 


\section{CASE REPORT}

constriction was felt and released by incising few cms along the lesser curve. Following this, the intestines were reduced to its normal anatomical position. The defect or rent was then closed after ruling out any other abnormalities in the intra-abdominal organs and abdominal wall.

RESULTS: The patient did well postoperatively and there were no untoward instances in the immediate or late post-operative period. The patient was discharged on the $11^{\text {th }}$ Post-operative day after suture removal.

DISCUSSION: Internal hernias were first described by Steinke in 1932.Internal hernias are a much rarer cause of Acute Intestinal Obstruction than external hernias or postoperative adhesions seen in only about 0.6 to $5.8 \%$ and amongst these, transomental hernias account for only about 1 - $4 \%$.They can be congenital or acquired (trauma, inflammation, age related atrophy). It is a possible provisional diagnosis in a patient with Acute Intestinal Obstruction with no history of previous surgery. The types of internal hernias include:

1. Paraduodenal (Most common) hernia.

2. Lesser sac (Foramen of Winslow) hernia.

3. Transmesenteric hernia.

4. Pericaecal hernia.

5. Sigmoid mesocolon hernia.

6. Supravesical hernia.

7. Pelvic hernia.

8. Transomental hernia.

They are congenital accounting for more than half the cases. Transomental hernias mostly occur on the Rt. Side of greater omentum. The origin of the defect may be congenital or acquired. This patient had no history of abdominal trauma. The pathology didn't seem to be due to an inflammatory cause or adhesions; epiploic appendixes were normal. Yamaguchi ${ }^{7}$ has classified Transomental hernias as Type A, B and C.

Type A: Peritoneal Cavity -> Greater omentum -> Peritoneal Cavity.

Type B: Peritoneal Cavity -> Omental bursa -> Peritoneal Cavity.

Type C: Peritoneal Cavity -> Omental bursa [C0].

-> Omental bursa -> Winslow's pouch -> Peritoneal Cavity [C2].

-> Omental bursa -> Lesser omentum -> Peritoneal Cavity [C3].

Though currently there are no specific investigations to rule out internal hernias, due to recent advances in CT8,9,10,11 and study of the various cases, we see the characteristic findings of the radial distribution of the mesentery which represents the convergence of the mesenteric vessels and the localized small intestine over the colon.8,9,10,11

CONCLUSION: Thus in cases of Acute or Sub Acute Intestinal Obstruction, an internal herniation cannot be ruled out, be it congenital or acquired. 


\section{REFERENCES:}

1. Newsom B.D, Kukora J. S Congenital ad acquired internal hernias: unusual causes of small bowel obstruction. Am J Surg. 1986;152:279-285. [PubMed]

2. Steinke CR: Internal hernia: Three additional case reports. Arch. Surg. 25: 909-925, 1932.

3. Li. J.C, Chu D.W, Lee D.W, Chan A.C. Small bowel intestinal obstruction caused by an unusual internal hernia. Asian J Surg. 2005; 28:62-64.

4. Stewart JOR:Transepiploic hernia. Brit J Surg 49: 649-652, 1962.

5. Junji AMANO: Diagnosis and treatment of internal hernia. Surgery MOOK, Kanehara \& Co., Tokyo 52:85-96, 1989 (in Japanese).

6. Hull J.D:Transomental hernia causing intestinal obstruction in elderly patient. Postgrad. Med. J. 59: 790, 1983.

7. Yamaguchi T.: A case of incarceration of sigmoid colon into hiatus of greater omentum. Rinsho Geka 33: 1041-1045, 1978 (in Japanese).

8. Uehara $\mathrm{K}$, Hasegawa $\mathrm{H}$, Ogiso $\mathrm{S}$ et al.: A case of transepiploic hernia successfully diagnosed preoperatively. Nihonrinshogeka 60(7): 1930-1933, 1999 (in Japanese).

9. Takada T, Yoshida H, Tsukada M, et al.: A Case of Transomental Hernia in a 95 year old woman. Jp. J Gastroenterol Surg 34: 244-248, 2001 (in Japanese).

10. Nakashima Y, Tachibana M, Yamaguchi E et al.: A case of transomental hernia diagnosed preoperatively by abdominal CT scan. Ninhorinshogeka 67 (10): 2490-2493, 2006 9in Japanese).

11. Delabrousse E, Couvreur M, Saguet 0 et al.: Strangulated transomental hernia: CT findings. Abdom Imaging 26 (1): 86-88, 2001.

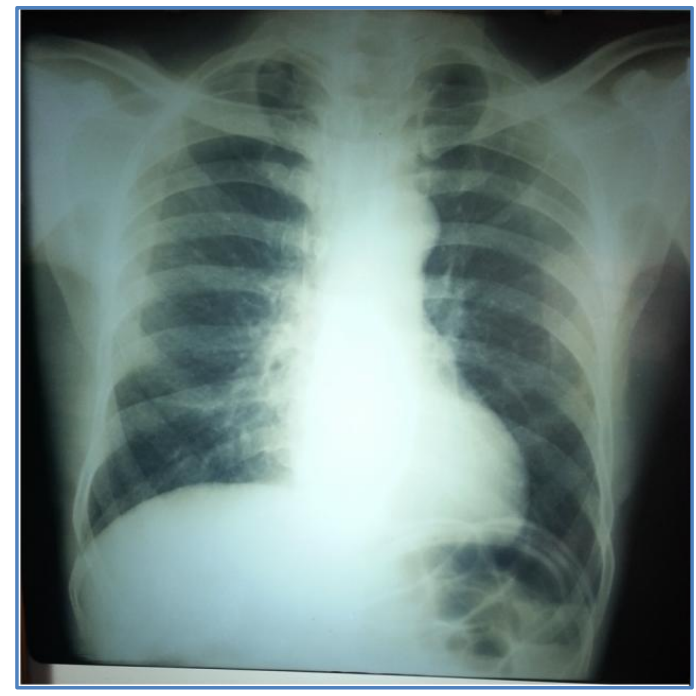

Fig. 1

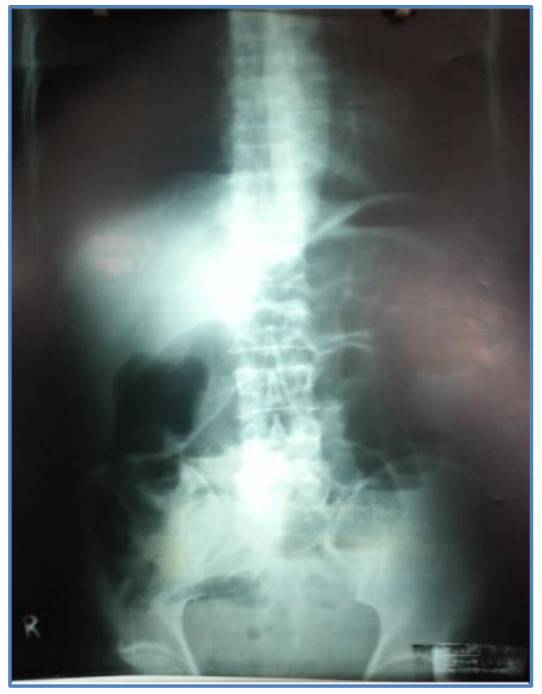

Fig. 2 


\section{CASE REPORT}

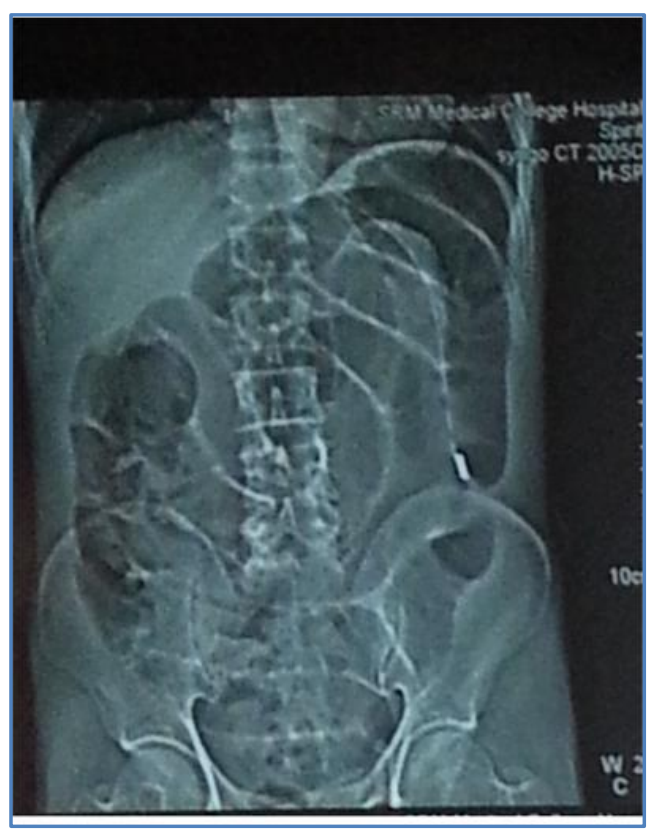

Fig. 3

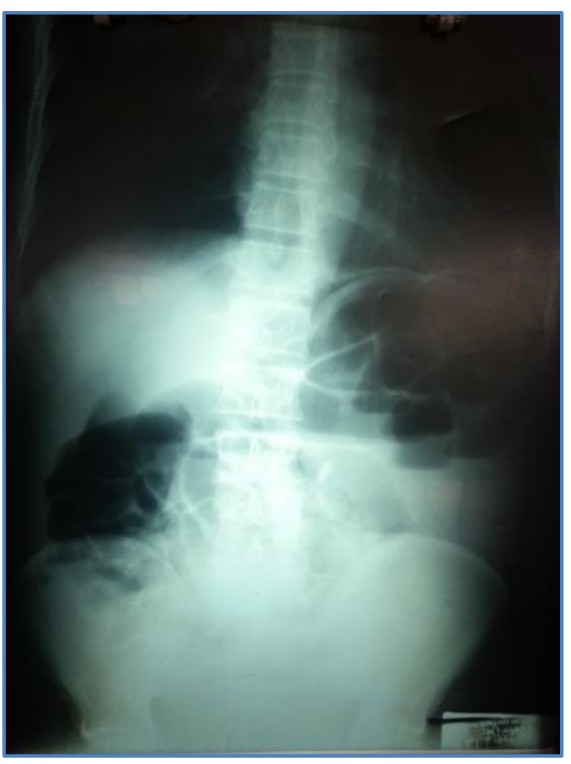

Fig. 5

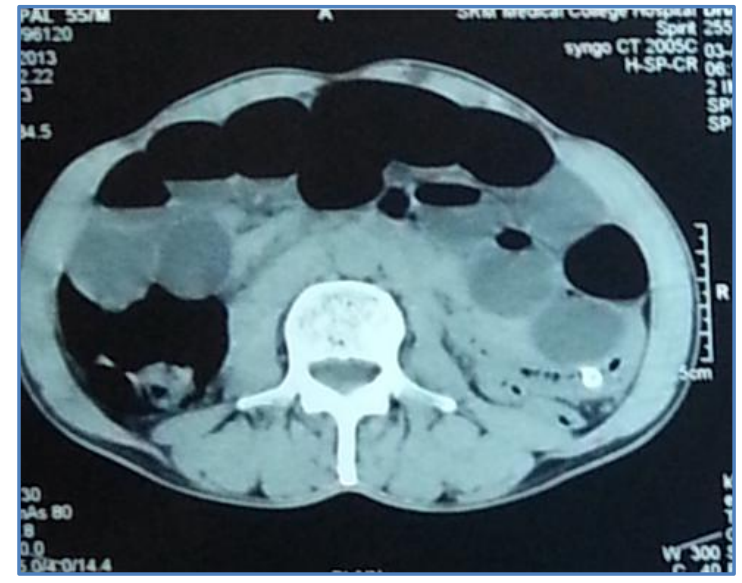

Fig. 4

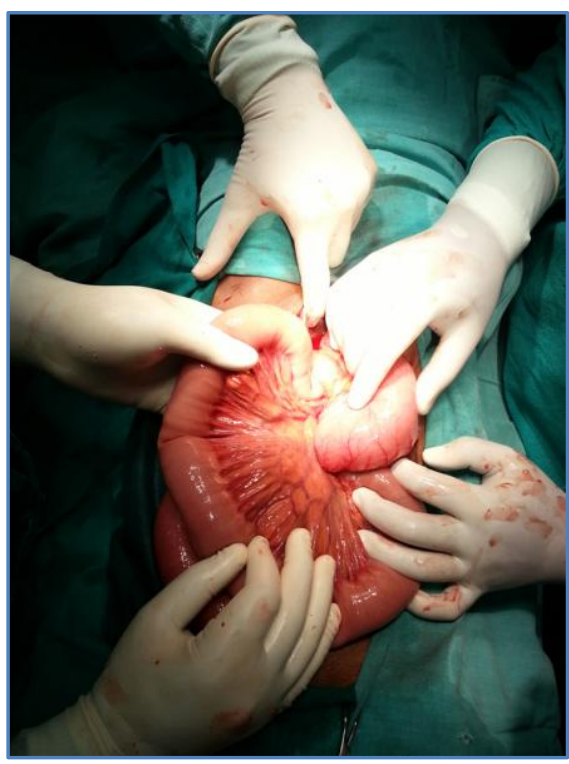

Fig. 6 


\section{CASE REPORT}

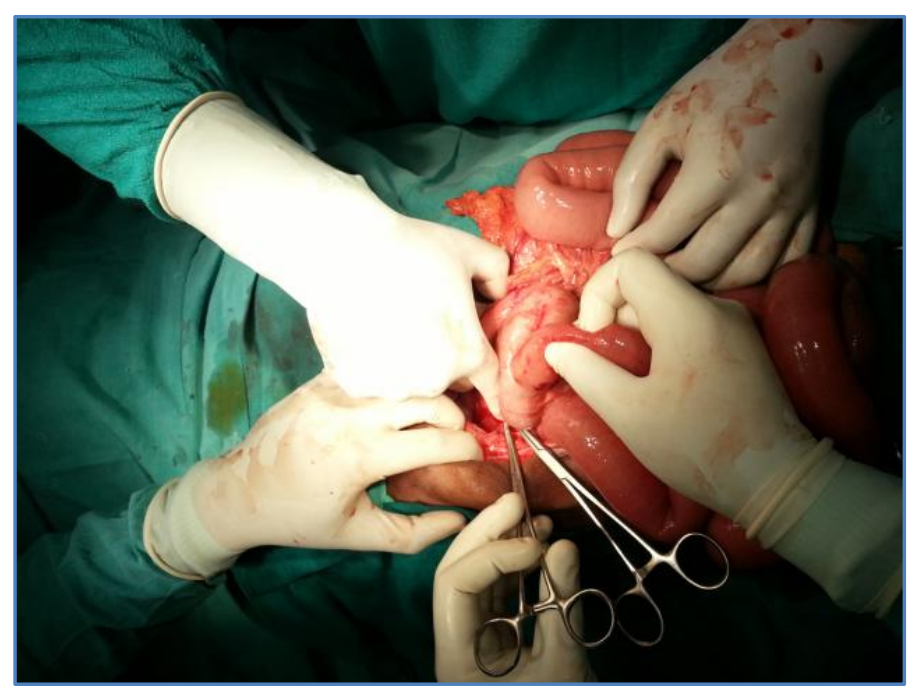

\section{Fig. 7}

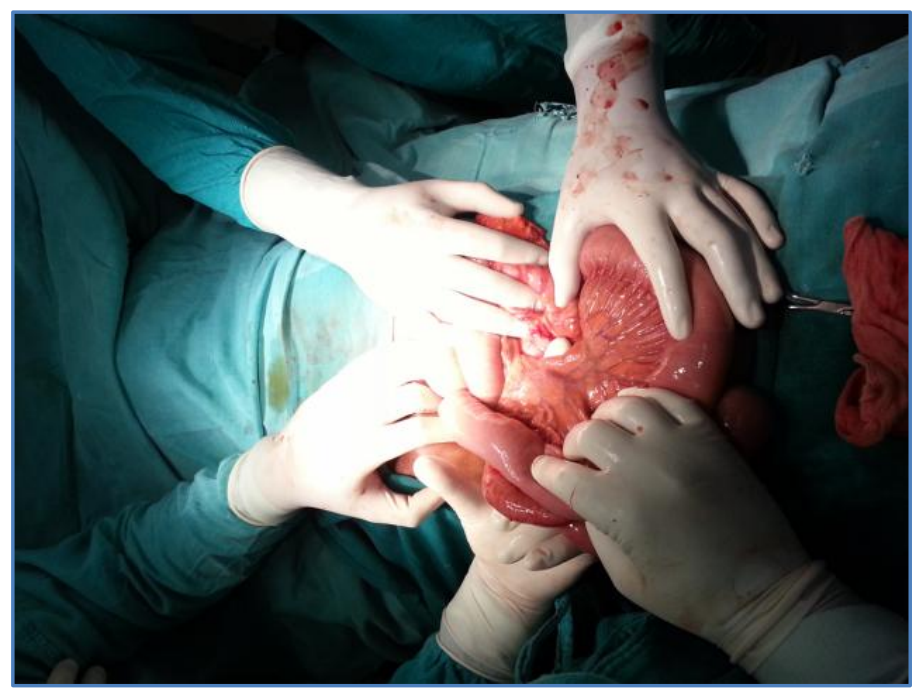

Fig. 8 


\section{AUTHORS:}

1. N. Suresh Kumar

2. Rahul Rai

3. P. Kulandai Velu

\section{PARTICULARS OF CONTRIBUTORS:}

1. Associate Professor, Department of General Surgery, SRM Medical College and Hospital, Kattankulathur, SRM University, Tamilnadu.

2. Post Graduate, Department of General Surgery, SRM Medical College and Hospital, Kattankulathur, SRM University, Tamilnadu.

FINANCIAL OR OTHER COMPETING INTERESTS: None
3. Professor, Department of General Surgery, SRM Medical College and Hospital, Kattankulathur, SRM University, Tamilnadu.

\section{NAME ADDRESS EMAIL ID OF THE CORRESPONDING AUTHOR:}

Dr. N. Suresh Kumar, \#322/36, Kadhiravan Colony, Annanagar, Chennai-600040.

E-mail: nagansuresh@gmail.com

Date of Submission: 06/02/2015. Date of Peer Review: 07/02/2015. Date of Acceptance: 12/02/2015. Date of Publishing: 19/02/2015. 